\title{
Apocrine adenosis: a precursor of aggressive breast cancer?
}

\author{
C A Wells, I L McGregor, C N Makunura, P Yeomans, J D Davies
}

\begin{abstract}
Aim-To investigate overexpression of cerbB2, expression of the $p 53$ protein product and proliferation rates in benign breast lesions with specific reference to apocrine adenosis.

Methods-Twenty one cases of apocrine adenosis were stained with monoclonal antibodies to $\mathrm{p} 185$, the protein product of the $c-e r b B 2$ oncogene, the protein product of the p53 tumour suppressor gene and to the cell cycle related protein Ki67. Three cases were associated with concomitant ductal carcinoma in situ of large cell type and two were associated with invasive tubular or cribriform carcinoma.

Results-Twelve $(57 \cdot 1 \%)$ cases showed membrane staining for c-erbB2 oncoprotein of apocrine cells within sclerosing adenosis and six $(28 \cdot 6 \%)$ had occasional p53 protein positive cells. One case not associated with carcinoma showed extensive staining of apocrine metaplasia outside the area of apocrine adenosis. The proliferation rate, as measured by Ki67 staining, was increased in some of the lesions and all lesions showed at least some of the cells to be in the cell cycle.
\end{abstract}

Conclusions - The expression of abnormal oncogene products and increased proliferation in some of these apocrine lesions questions the supposed degenerative nature of the atypia seen in such cases and suggests that there may be an association between these lesions and large cell ductal carcinoma in situ and hence invasive carcinoma.

(f Clin Pathol 1995;48:737-742)

Keywords: Breast, apocrine metaplasia, apocrine adenosis, oncogene expression, breast cancer.

Department of

Histopathology,

St Bartholomew's

Hospital,

West Smithfield

London EC1A 7BE

C A Wells

I L McGregor

C N Makunura

P Yeomans

Regional Breast

Pathology Unit,

University of Bristol,

Bristol

J D Davies

Correspondence to:

Dr C A Wells.

Accepted for publication

21 February 1995

Several studies have emphasised the increased risk of subsequent breast carcinoma associated with fibrocystic change of about $\times 2.5$ seen epidemiologically. ${ }^{1}$ Some studies have indeed identified lesions which carry an increased incidence of subsequent malignancy such as atypical ductal hyperplasia, ${ }^{23}$ atypical lobular hyperplasia ${ }^{4}$ and multiple papillomas. ${ }^{5}$ Most of these lesions develop into small cell micropapillary or cribriform carcinoma in situ and thereafter into invasive ductal or lobular carcinoma. Precursor lesions for large cell comedo or solid type ductal carcinoma in situ have not been identified as yet.
$\mathrm{C}-e r b \mathrm{~B} 2$ is an oncogene present on chromosome $17 \mathrm{q}$ which codes for a $185 \mathrm{kDa}$ protein (p185) with tyrosine kinase receptor function analogous to the epidermal growth factor receptor. The p185 receptor is overexpressed in about $20 \%$ of invasive breast carcinomas ${ }^{67}$ but is more frequently overexpressed in large cell comedo carcinoma in situ $^{8}$ in about $80 \%$ of cases. It has been postulated that overexpression of this oncoprotein is an early event in the genesis of some types of breast carcinoma and that subsequently the receptor may be lost once a tumour has become invasive.

p53 is a tumour suppressor gene which is present on chromosome $17 \mathrm{p}$. This gene codes for a protein which is mutated in certain families as a genetic event associated with childhood sarcomas and ovarian carcinoma. ${ }^{9}$ It is also found as a sporadic event in some breast carcinomas known not to be familial. The wildtype protein has a short half life and is not normally detected by immunocytochemistry except in extreme cases of DNA damage, but mutant forms of the protein may accumulate and become detectable. ${ }^{10}$

$\mathrm{Ki} 67$ is an antibody that recognises a cell cycle related nuclear antigen, which is thought to be expressed in the $G 1, S, G 2$, and $M$ phases of the cell cycle but not in G0. ${ }^{11}$ Percentage scores for carcinomas have been shown to vary with the type of tumour from $2 \cdot 25 \%$ in tubular carcinoma to $63.95 \%$ in others. ${ }^{12}$

We have studied 21 cases of apocrine adenosis, three associated with ductal carcinoma in situ and two with invasive carcinoma, by immunocytochemistry using antibodies to the c-erbB2 oncoprotein, p53 protein and the proliferation related antigen Ki67. Control cases of normal breast tissue, apocrine metaplasia and sclerosing adenosis were also studied to determine the level of proliferation, c-erbB2 oncoprotein expression and p53 positivity in these conditions in the absence of apocrine adenosis.

\section{Methods}

Cases of apocrine adenosis (figs 1 and 2) were collected from the files of the histopathology departments of St Bartholomew's Hospital, London, and Southmead Hospital Breast Pathology Unit. Some of these cases had been sent to CAW and JDD as referrals. The details of the cases are given in table 1 . An unselected series of 48 cases of apocrine metaplasia, 36 cases of normal breast tissue and 25 cases of sclerosing adenosis without apocrine adenosis were also stained with the same antibodies. 


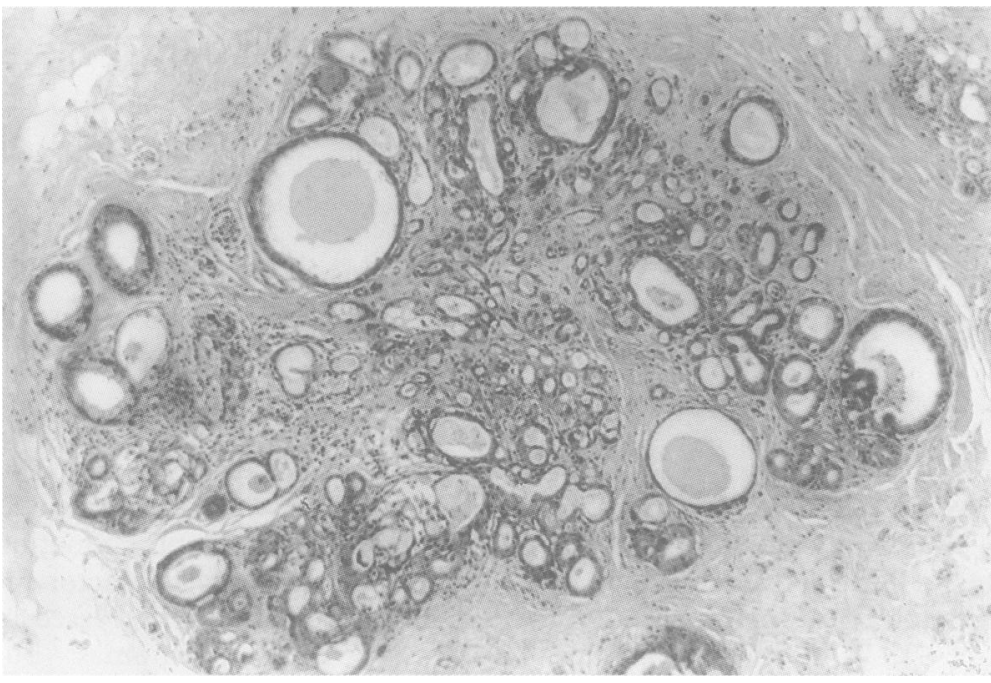

Figure 1 Apocrine adenosis in a lobule associated with sclerosing adenosis. Haematoxylin and eosin; $\times 10$.

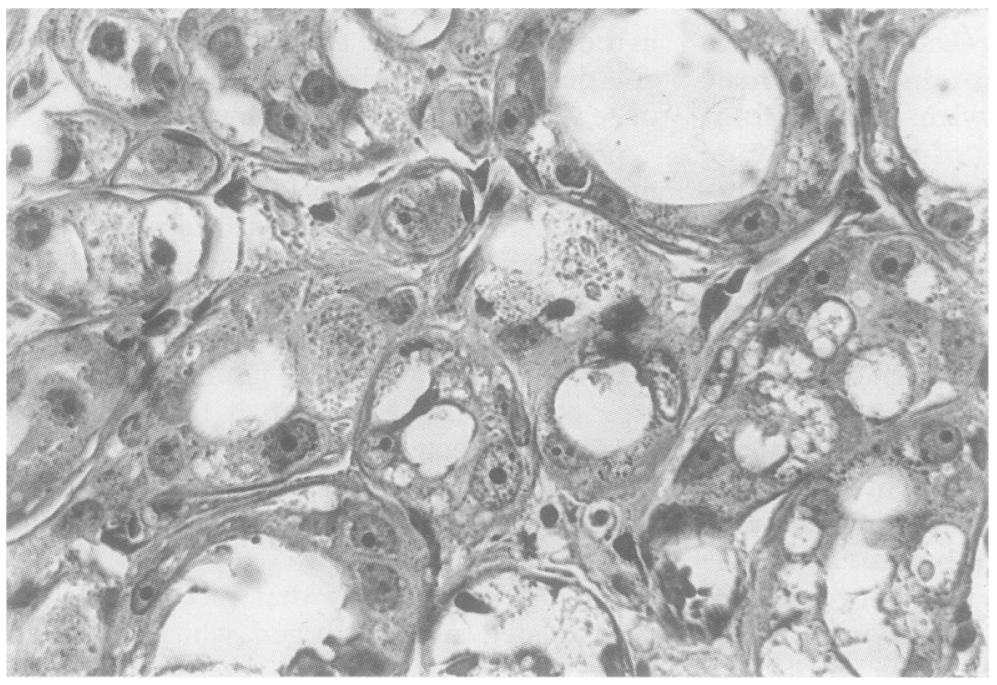

Figure 2 Apocrine adenosis at higher magnification showing cytological atypia. Haematoxylin and eosin; $\times 150$.

\section{Immunocytochemistry \\ TISSUE}

Formol saline fixed, paraffin wax embedded blocks of apocrine adenosis were selected from the files and sectioned at a nominal $4 \mu \mathrm{m}$. The standard avidin biotin complex (ABC) method ${ }^{13}$ was used. Appropriate negative controls omitting the primary antibodies were included.

\section{ANTIBODIES}

c-erbB2

A mouse monoclonal antibody raised against the $\mathrm{p} 185$ protein product of the c-erbB 2 oncogene (Clone NCL-CB11; Novocastra, Newcastle, UK) was used at a dilution of 1 in 200 . The primary antibody was applied overnight at $3^{\circ} \mathrm{C}$ and a previously stained positive breast carcinoma was used as a positive control.

\section{p53}

A mouse monoclonal antibody raised against recombinant p53 protein (Clone DO-7; Novocastra) was used at a dilution of 1 in 50 . The primary antibody was applied overnight at $3^{\circ} \mathrm{C}$ and a previously stained weakly positive breast carcinoma was used as a positive control.

\section{Ki67}

A polyclonal rabbit anti-human $\mathrm{Ki} 67$ antigen (Dako, High Wycombe, UK) was used at a dilution of 1 in 50 for 30 minutes. The ABC technique was modified with a digestion stage prior to the application of the first layer, involving heating for one minute under high pressure in citrate buffer at $\mathrm{pH} 6.0$ as an alternative to microwave treatment. ${ }^{14}$ Germinal centres of tonsil sections were used as a positive control. A total of 200 or 300 cells, depending on the size of the lesion, were counted within the area of apocrine adenosis by two observers and the percentage of positive cells calculated.

\section{Results}

C-erbB2 ONCOGENE PRODUCT

Positive cell membrane staining was seen in the areas of apocrine adenosis in $12(57 \cdot 1 \%)$ of the 21 cases. This was classed as strong staining in four cases (fig 3) and as weak in eight. One of the cases with strong staining also showed strong staining of otherwise unremarkable papillary apocrine metaplasia

Table 1 Case details

\begin{tabular}{llll}
\hline Patient number & Age (years) & Clinical history & Histological features \\
\hline 1 & 54 & Microcalcification on screening mammogram & Fibrocystic changes, papillary apocrine metaplasia, AA \\
2 & 52 & Stellate lesion with microcalcification on screening mammogram & Radial scar, atypical ductal hyperplasia, AA \\
3 & 58 & Stellate lesion on screening mammogram & Radial scar, AA \\
4 & 43 & Bilateral breast lumps close to nipple & Fibroadenoma, papillary apocrine metaplasia, AA \\
5 & 60 & Impalpable lesion with microcalcification & Fibroadenoma, radial scar, AA \\
6 & 42 & Blood stained nipple discharge and tenderness & Fibrocystic changes, sclerosing adenosis, AA \\
7 & 50 & Impalpable stellate lesion on screening mammogram & Complex sclerosing lesion, AA \\
8 & 32 & Clinical fibroadenoma & Fibrocystic changes, sclerosing adenosis, AA \\
9 & 52 & Palpable lump with stellate lesion on screening mammogram & Radial scar, AA \\
10 & 85 & Palpable mass close to nipple & AA \\
11 & 63 & Stromal deformity on screening mammogram & Radial scar, AA \\
12 & 48 & Microcalcification on screening mammogram & Atypical ductal hyperplasia, AA \\
13 & 46 & Clinically bilateral fibrocystic change: microcalcification on mamogram Sclerosing adenosis, hyperplasia, AA \\
14 & 39 & Increasing density on serial mammograms & Fibrocystic changes, radial scar, AA \\
15 & NK & Stellate lesion on screening mammogram & Radial scar, AA \\
16 & 63 & Case details unavailable & Fibrocystic changes, apocrine metaplasia, AA \\
17 & 51 & Stellate lesion on mammogram & Radial scar, apocrine ductal carcinoma in situ, AA \\
18 & 51 & Indeterminate microcalcification on screening mammogram & Apocrine duct carcinoma in situ, AA \\
19 & 51 & Palpable lump in breast & Tubular carcinoma, small cell solid ductal carcinoma in situ, AA \\
20 & 56 & Stromal deformity on screening mammogram & Invasive cribriform carcinoma, AA \\
21 & 65 & Microcalcification and vague density on mammogram & Ductal carcinoma in situ, AA \\
\hline
\end{tabular}




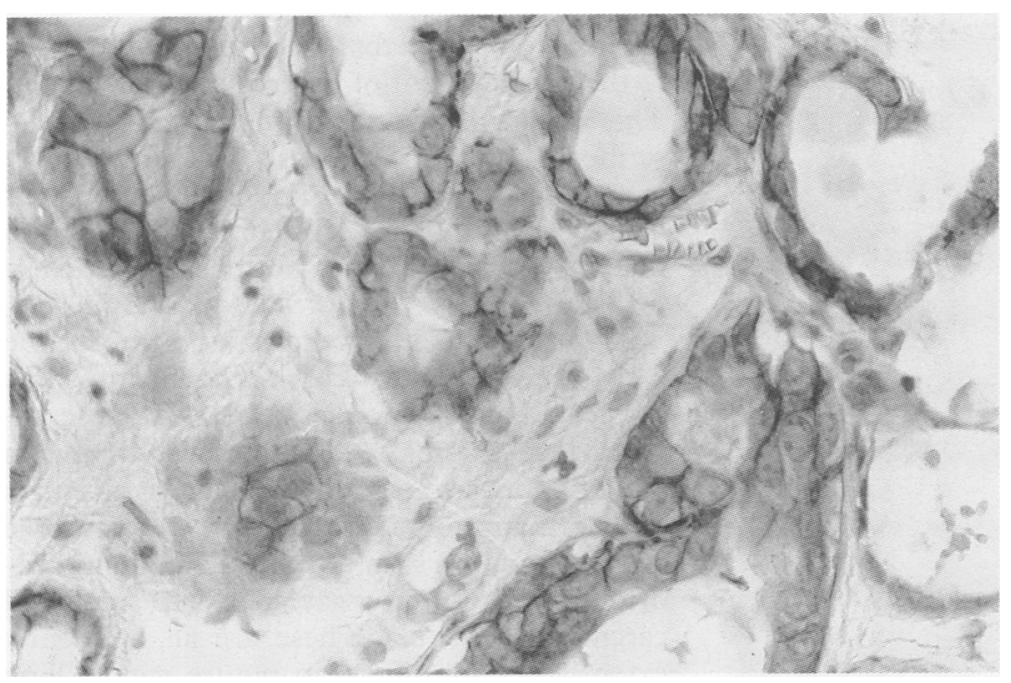

Figure $3 C$-erbB2 immunostaining in an area of apocrine adenosis showing membrane staining for the protein product $p 185$. Immunoperoxidase; $\times 150$.

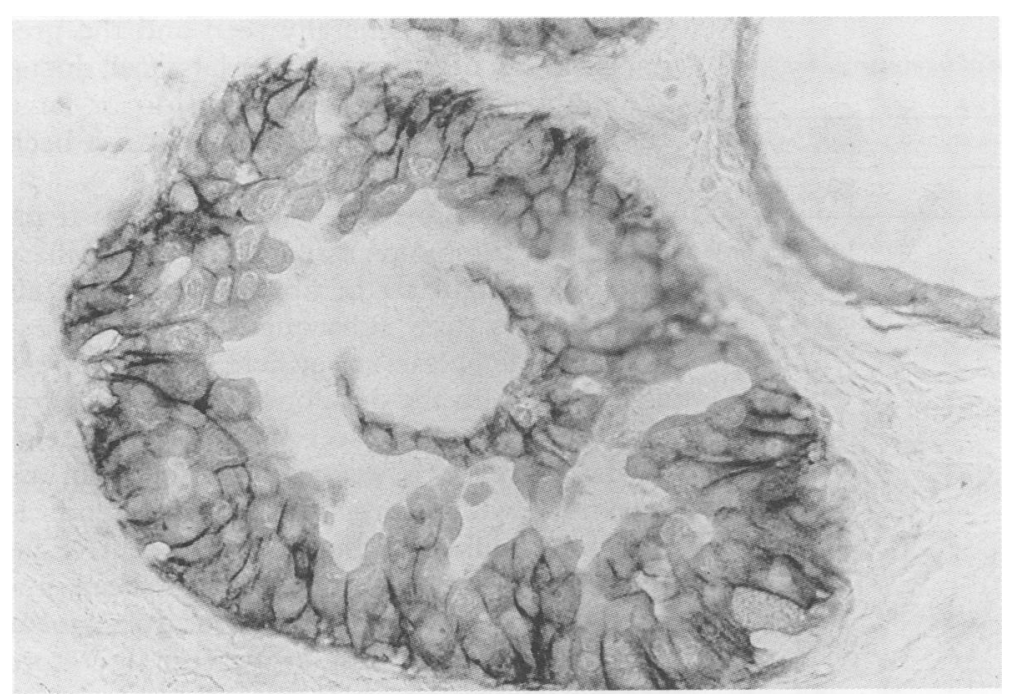

Figure 4 C-erbB2 immunostaining in unremarkable papillary apocrine metaplasia outside the area of apocrine adenosis in case 1 . Immunoperoxidase; $\times 150$.

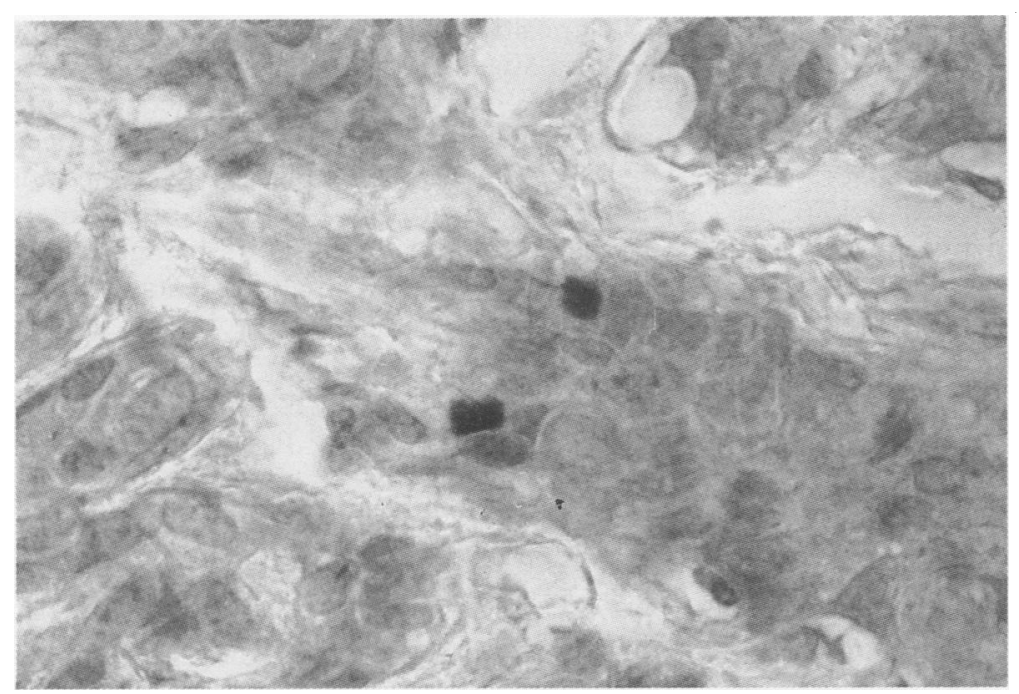

Figure 5 p53 staining of an area of apocrine adenosis showing nuclear positivity. Immunoperoxidase; $\times 400$.

throughout the tissue (fig 4), a finding not seen in the other cases. Some cases also showed cytoplasmic staining of the apocrine cells, two of which showed membrane staining. Cytoplasmic staining only was counted as neg- ative. Of the three cases with associated ductal carcinoma in situ, two showed negative staining in both the apocrine adenosis and the carcinoma, and the other showed positive staining in both the apocrine adenosis and in the tumour. The case of invasive tubular carcinoma with small cell solid ductal carcinoma in situ did not show staining of either the apocrine adenosis adjacent to the tumour or in the tumour proper. In one area, however, there was a mixture of cells resembling the cells within the carcinoma in situ and cytologically atypical apocrine cells. In this area membrane staining of the apocrine cells was noted, while the carcinoma cells were negative. The case associated with invasive cribriform carcinoma showed no staining of either the tumour or the apocrine adenosis.

Three $(6 \cdot 25 \%)$ of the 48 control cases of apocrine metaplasia showed weak membrane staining of apocrine metaplastic cells. Two of these cases were associated with fibroadenoma while one was associated with atypical ductal hyperplasia, although the atypical lesion itself was negative. Seven cases showed cytoplasmic staining only and the rest were completely unstained. Cytoplasmic staining was scored negative as before. Sclerosing adenosis and normal epithelium were uniformly negative in all cases.

\section{P53}

On immunostaining with the monoclonal antibody to $\mathrm{p} 53$ protein, only one case of apocrine adenosis contained a focal area of cells staining with p53 in a pattern akin to that seen in invasive carcinomas (fig 5). A further five cases, however, showed occasional cells with nuclear positivity for p53. These cases did not necessarily show positivity for c-erbB2 oncoprotein. The case showing strong staining for c-erbB2 in papillary apocrine metaplasia showed strong cytoplasmic staining for p53 protein and focal nuclear staining. Thirty five cases of apocrine metaplasia were tested for abnormal p53 expression by immunostaining. No staining was observed in any case. Normal epithelium and sclerosing adenosis without apocrine adenosis were also negative.

\section{KI67}

Fifteen cases of apocrine adenosis not associated with carcinoma were suitable for staining with the $\mathrm{Ki} 67$ antibody. The mean percentage positivity of these lesions was $5.0 \%$ (range 0.5 to $14.5 \%$ ) (fig 6). Four of the five cases associated with carcinoma were stained with the $\mathrm{Ki} 67$ antibody and these showed a mean percentage positivity of $8.06 \%$ (range 2.7 to $14.8 \%)$. The results are summarised in table 2 .

The 36 control cases of normal breast epithelium stained had a mean positivity of $0.93 \%$ (range 0 to $7 \%$ ). Twenty eight cases of unselected apocrine metaplasia showed a mean percentage positivity of $1 \cdot 1 \%$ (range 0 to $9 \%$ ). Twenty five cases of unselected sclerosing adenosis had a mean positivity of $\mathbf{4 \cdot 8 \%}$ (range 0 to $17 \%$ ). This was primarily due to two cases, 


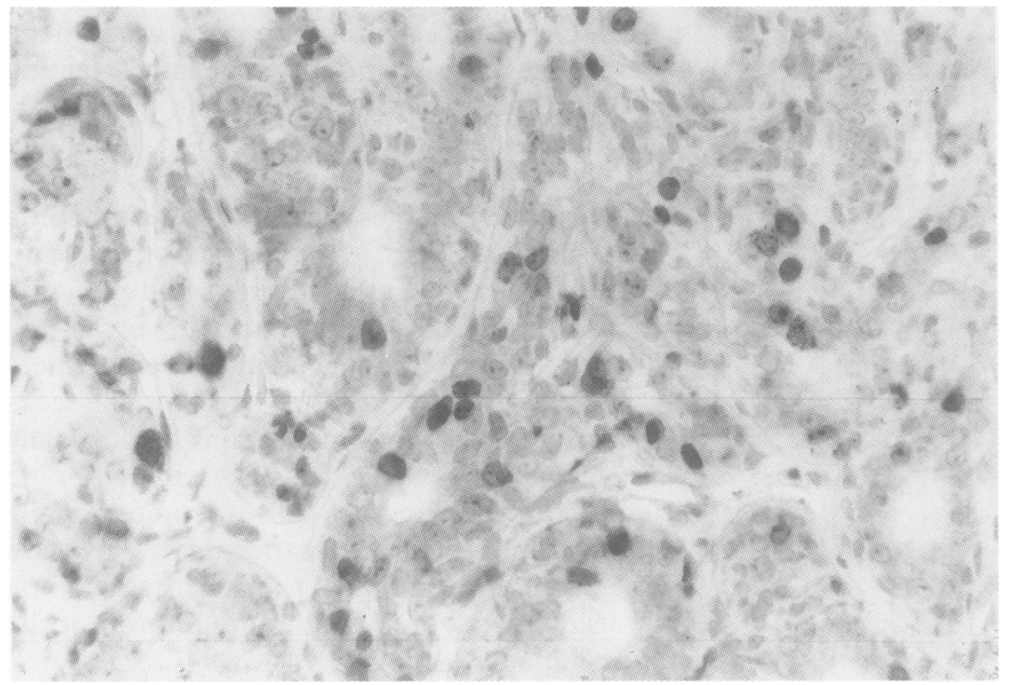

Figure 6 Ki67 staining of apocrine adenosis showing numerous cells in the cell cycle. Immunoperoxidase; $\times 100$. or leiomyomas and that the atypia are unrelated to the development of subsequent malignancy. This lesion is distinct from the changes described as apocrine adenosis by Eusebi et $a l^{16}$ in adenomyoepithelioma and in the differential diagnosis of tubular carcinoma. ${ }^{17}$ Their particular type of lesion has not been included in this study.

Atypical lobular hyperplasia resembles the early stages of lobular carcinoma in situ, while atypical ductal hyperplasia bears a close resemblance to small cell ductal carcinoma in situ of cribriform or micropapillary type and is not normally found in association with large cell carcinoma in situ. ${ }^{18}$ Multiple papilloma syndrome is also often associated with small cell carcinoma in situ. ${ }^{19}$ These are all frequently extensive or multifocal in nature with a long time course to the development of carcinoma. Although there may be a progression from small cell to large cell carcinoma in situ in some cases, this is not generally seen and the precursor lesion of the commoner large cell ductal carcinoma in situ of solid, comedo or large cell micropapillary type has thus far not been identified.

Haagensen ${ }^{20}$ found a fivefold increased incidence of carcinoma associated with papillary apocrine metaplasia in fibrocystic change although this has subsequently been questioned..$^{21}$ Metaplasias elsewhere in the body are associated with the development of carcinoma in lung, stomach or cervix. Apocrine metaplasia, however, is extremely common in association with fibrocystic change and is therefore unlikely to be a direct precursor lesion. Sclerosing adenosis has also been implicated in an increased risk of subsequent breast carcinoma ${ }^{22}$ but as yet the literature has not suggested an increased incidence of malignancy associated with apocrine adenosis. ${ }^{23}$ However, the follow up period for these lesions in the literature is rather short.

The positive staining for c-erbB 2 in apocrine adenosis suggests that at least some of these lesions are overexpressing this oncogene and hence may not be degenerative as has been suggested. ${ }^{15}$ The percentage of these lesions showing positivity for c-erbB2 oncoprotein $(57 \cdot 1 \%)$ is unprecedented for a benign lesion. Lodato et $a l^{24}$ found a small percentage (10\%) of positive cases among a group of atypical hyperplasias but Gusterson et $a l^{25}$ found no cases of benign lesions overexpressing the oncoprotein in a series of 149 patients. In most of the cases in this series apocrine metaplasia outside the lesion has not been shown to overexpress the oncoprotein and the series of unselected cases of apocrine metaplasia stained for c-erbB2 do not generally show overexpression. An interesting finding, therefore, is that in four cases studied here, one of which was associated with apocrine adenosis, otherwise unremarkable apocrine metaplasia also overexpressed the oncogene (fig 4). This has been noted before by McCann et $a^{26}$ in one of 45 benign breast samples.

Accumulation of p53 protein in the nuclei of cells within areas of apocrine adenosis is also unusual for a benign lesion, but is commonly 2) which are seen within areas of scler adenosis and occasionally within terminal ducts. It has been generally assumed that these atypical changes are degenerative, akin to the atypical changes seen in ancient Schwannomas 
seen in carcinomas. ${ }^{9}$ Antibody detection of accumulated protein is generally thought to be related to the formation of a mutant protein which is not destroyed effectively. Very sensitive enhanced immunocytochemical techniques could theoretically detect small amounts of the wild-type protein especially in lesions with DNA damage; however, the method used here is the standard technique without enhancement and no positive cases were detected among the unselected cases of apocrine metaplasia, normal epithelium or sclerosing adenosis. The finding, therefore, of some cases showing accumulation of immunoreactive protein suggests that some of these cases may have a mutation in the p53 gene. The antibody used cannot detect cases where both alleles of the p53 gene are absent and hence the protein is not being produced, and the antibody may also not detect occasional cases where mutation is in the region recognised by the antibody.

Abnormal oncogene expression by apocrine cells has been suggested before ${ }^{27}$ using antibodies to ras and c-myc. Increased proliferation, however, has not been shown to be a feature of apocrine metaplasia ${ }^{28}$ and some authors believe that apocrine metaplasia in general is a terminally differentiated lesion, ${ }^{2829}$ a suggestion generally supported by the low proliferation rate in the unselected series of apocrine metaplasia tested here. Apocrine adenosis, however, has not been specifically studied using these methods. The results of the Ki67 staining in these lesions is variable but four cases not associated with carcinoma showed a marked increase in proliferation rate comparable with that found in some carcinomas. ${ }^{12}$ This suggests that in some of these specific lesions the apocrine cells are not necessarily terminally differentiated and are still undergoing proliferation. In the series of unselected apocrine metaplastic lesions two cases showed proliferation rates of 8 and $9 \%$, respectively. One of these was a case with cytoplasmic positivity for c-erbB2 and atypical ductal hyperplasia elsewhere in the tissue. The other was an unusual case of florid papillary apocrine metaplasia. Three cases of myoepithelial cell proliferation in the florid phase of sclerosing adenosis also showed high proliferation rates but epithelial proliferation was not a feature.

If the time course from the precursor lesion to the development of large cell ductal carcinoma in situ is short and the disease starts in a unifocal fashion spreading down the duct system and becoming invasive in multiple areas, as is seen in some large cell ductal carcinomas in situ detected by breast cancer screening, then the precursor lesion is likely to be a rare phenomenon. If this putative precursor lesion was unifocal and completely or partially excised and subsequently destroyed by the tissue reaction to surgery, it may well be eradicated and the premalignant nature of the lesion may go unrecognised in long term follow up studies.

If apocrine adenosis was to be associated with large cell ductal carcinoma in situ, then it may be possible to find areas of apocrine adenosis associated with ductal carcinoma. If, however, the tumour is extensive, then sam- pling errors may not find small areas of apocrine adenosis and there are no reports, to our knowledge, in the literature where such an extensive search has been carried out.

It is interesting that three of our cases are intimately associated with large cell duct carcinoma in situ and this association may become more apparent as further cases of early large cell ductal carcinoma in situ accrue from the incident rounds of breast cancer screening programmes. One feature of our series, however, is that the two cases identified in association with invasive carcinoma were associated with tumours of the small cell type with a tubular or cribriform pattern. These associations observed in the small numbers studied here may have occurred by chance.

The results of abnormal oncogene expression and increased proliferation in these lesions and the previous findings of abnormal ras and c$m y c$ expression in apocrine metaplasia suggest that further work on the possible premalignant nature of apocrine lesions should be performed.

We are most grateful to Drs K Agarwal (Epping), T I F McLeod (Bath), N Gubbay (Cheltenham), Paul Conn (Colchester) and Professor P P Anthony (Exeter) for allowing us to examine and report referred cases. We are also indebted to $\mathrm{Mr} \mathrm{P}$ Crocker and $\mathrm{Mr} J$ Hopwood for photographic assistance. This study was supported by the Joint Research Board of St Bartholomew's sorted (IIM) Jnd in part by the Cancer Research Committe of St Bartholomew's Hospital (PY) and the SW RHA R \& D Board (JDD).

1 Vessey M. A review of the risk factors. Rev Endocrinol Related Cancer 1982;10(Suppl):41-8.

2 Dupont WD, Page DL. Risk factors for breast cancer in women with proliferative breast disease. $N$ Engl $\mathcal{F} \mathrm{Med}$ 1985;312:146-51.

3 Tavassoli FA, Norris HJ. A comparison of the results of long term follow-up for atypical intraductal hyperplasia and intraductal hyperplasia of the breast. Cancer 1990;65: 518-29.

4 Page DL, Dupont WD, Rogers LW. Ductal involvement by cells of atypical lobular hyperplasia in the breast. Hum Pathol 1987;19:201-7.

5 Haagensen CD, Bodian C, Haagensen DE. Breast cancer risk and detection. Philadelphia: WB Saunders, 1981:70-5.

6 Soomro S, Shousha S, Taylor P, Shepard HM, Feldmann $M$. c-erbB-2 expression in different histological types of invasive breast carcinoma. F Clin Pathol 1991;44:211-14. invasive breast carcinoma. F Clin Pathol 1991;44:211-14.
Gusterson BA, Machin LG, Gullick WJ, Gibbs NM, Powles TJ, Price P, et al. Immunohistochemical distribution of cerb-B2 in infiltrating and in-situ breast cancer. Int $\mathcal{f}$ Cancer 1988;42:842-5.

8 Bartkova J, Barnes DM, Millis RR, Gullick WJ. Immunohistochemical detection of c-erb-B2 protein in mammary ductal carcinoma in-situ. Hum Pathol 1990;21: 1164-7.

9 Harris A. Mutant p53-the commonest genetic event in human cancer? $\mathcal{F}$ Pathol 1990;162:5-6.

10 Lane DP, Benchimol S. p53: Oncogene or antioncogene? Genes Dev 1990;4:1-8.

11 Gerdes J, Lemke H, Baisch H, Wacker HH, Schwab U, Stein $H$. Cell cycle analysis of a cell proliferation associated human nuclear antigen defined by the monoclonal antibody Ki67. F Immunol 1984;133:1710-16.

12 Barnard NJ, Hall PA, Lemoine NR, Kadar N. Proliferative index in breast carcinoma determined in-situ by Ki67 immunostaining and its relationship to clinical and pathological variables. $₹$ Pathol 1987;152:287-95.

13 Hsu S-M, Raine L, Fanger H. Use of avidin-biotin-peroxidase complex (ABC) in immunoperoxidase techniques: a comparison between $\mathrm{ABC}$ and unlabelled antibody (PAP) procedures. $₹$ Histochem Cytochem 1981;29:577-80.

14 Norton AJ, Jordan S, Yeomans P. Brief, high-temperature heat denaturation (pressure cooking): a simple and effective method of antigen retrieval for routinely processed tissues. F Pathol 1994;173:371-9.

15 Simpson JF, Page DL, Dupont WD. Apocrine adenosis-a mimic of mammary carcinoma. Surg Pathol 1990;3:28999.

16 Eusebi V, Casadei GP, Bussolati G, Azzopardi JG. Adenomyoepithelioma of the breast with a distinctive type of apocrine adenosis. Histopathology 1987;11:305-15.

17 Eusebi V, Foschini MP, Betts CM, Gherardi G, Millis RR, Bussolati $\mathrm{G}$, et al. Microglandular adenosis, apocrine adenosis, and tubular carcinoma of the breast. An immunohistochemical comparison. Am $\mathcal{f}$ Surg Pathol 1993; 17:99-109.

18 Bellamy COC, McDonald C, Salter DM, Chetty U, Anderson TJ. Noninvasive ductal carcinoma of the breast: 
The relevance of histological categorization. Hum Pathol 1993;4:16-23.

19 Papotti M, Gugliotta P, Ghiringello B, Bussolati G. Association of breast carcinoma and multiple intraductal pociation of breast carcinoma and multiple intraductal papillomas: an histological and immunohisto

20 Haagensen CD. Apocrine Epithelium. In: Diseases of the breast. 3rd edn. Philadelphia: WB Saunders, 1986:82-101. breast. 3rd edn. Philadelphia: WB Saunders, 1986:82-101. 21 Cancer Committee of the College of American Pathologists.
Is "fibrocystic disease" of the breast precancerous? Arch Is "fibrocystic disease" of the breast
Pathol Lab Med 1986;110:171-3.

22 Jensen RA, Page DL, Dupont WD, Rogers LW. Invasive breast cancer risk in women with sclerosing adenosis. Cancer 1989;64:1977-83.

23 Carter DJ, Rosen PP. Atypical apocrine metaplasia in sclerosing lesions of the breast: a study of 51 patients. Mod Pathol 1991;4:1-5.

24 Lodato RF, Maguire HC, Greene MI, Weiner DB, LiVolsi VA. Immunohistochemical evaluation of c-erbB-2 oncogene expression in ductal carcinoma in situ and atypical ductal hyperplasia of the breast. Mod Pathol 1990;3:44954.

25 Gusterson BA, Machin LG, Gullick WJ, Gibbs NM, Powles TJ, Elliot $\mathrm{C}$, et al. C-erbB-2 expression in benign and TJ, Elliot $\mathrm{C}$, et al. C-erbB-2 expression in benign and 6 McCann A, Johnston PA, Dervan PA, Gullick WJ, Carney DN. c-erbB2 oncoprotein expression in malignant and non-malignant breast tissue. Ir f Med Sci 1989;158:13740.

27 Agnantis NJ, Mahera H, Maounis N, Spandidos DA. Immunohistochemical study of ras and myc oncoproteins in apocrine breast lesions with and without papillomatosis. Eur f Gynaecol Oncol 1992;13:309-15.

28 Bussolati G, Sapino A, Gugliotta P, Macri L. Cytological analysis of benign breast disease. Cancer Detect Prev 1992; 16:89-92.

29 Raju U, Zarbo RJ, Kubus J, Schultz DS. The histologic spectrum of apocrine breast proliferations: a comparative spectrum of apocrine breast proliferations: a comparative
study of morphology and DNA content by image analysis. Hum Pathol 1993;24:173-81. 